\title{
Preliminary Results on Cognitive Impairment in A Cohort of Greek Multiple Sclerosis Patients
}

\author{
Theodoros Koukoulidis ${ }^{2}$, Marianthi Arnaoutoglou ${ }^{1,2}$, Dimitrios Michmizos ${ }^{3}$, Stavros Baloyannis ${ }^{2}$ and Effrosyni \\ Koutsouraki ${ }^{1,2 *}$ \\ ${ }^{1}$ Department of Neurologic clinic, University Hospital AHEPA, Greece
}

${ }^{2}$ Department of Neurologic clinic, Aristotle University, Greece

${ }^{3}$ Department of Neurologic clinic, University of Thessaly, Greece

Submission: January 17, 2019; Published: March 13, 2019

*Corresponding author: Effrosyni Koutsouraki, Department of Neurologic clinic, University Hospital AHEPA, Thessaloniki, Greece

\section{Introduction}

Cognitive impairment is a common phenomenon in Multiple Sclerosis (MS), occurring at all stages of the disease, even at the earliest, and can be a major source of disability, social impairment, and impoverished quality of life. Cognitive dysfunction is mainly focused on working memory, conceptual reasoning, verbal fluency, speed of information processing, attention and executive functions. Additional clinical factors, including the progression of the disease, fatigue and affective disturbance, can impact the degree of MS-related cognitive impairment $[1,2]$.

Keywords: Multiple Sclerosis; Multiple sclerosis; Mini mental state; Expanded disability; Neuropsychologically; Antidepressants; Anonymously; Healthy controls; Memory; Daily routine; Lobes

Abbreviations: MS: Multiple Sclerosis; MMSE: Mini Mental State Examination; EDSS: Expanded Disability Status Scale

\section{Materials \& Methods}

We present the initial observations of a prospective study on cognitive impairment in a Greek cohort of MS patients, living in the Northern Greek city of Thessaloniki. For a 30-month period, in 6-months intervals, we followed clinically and neuropsychologically 40 patients with CDMS (revised diagnostic criteria Mc. Donald 2010) as well as 20 healthy controls matched for age and gender [3]. The clinical data we analyzed included: gender, age, family status, education, profession, duration of MS type of MS, the most affected parts of the CNS as indicated by their MRIs and Expanded Disability Status Scale (EDSS) scores.

For the neuropsychological evaluation we used interviews (with the patient as well as his family), the Mini Mental State Examination (MMSE), the SKT (Questionnaire for critical capacity and memory), the Hamilton scale (for depression), the BDI scale (for depression) and the GHQ-25 scale (for emotional disturbances).

\section{Inclusion criteria}

stable clinical course for at least one year

\section{Exclusion criteria}

severe emotional or cognitive disturbances from the beginning of the study, treatment with high doses of corticosteroids or antidepressants Patients and healthy controls were informed and agreed to participate in the above study, anonymously.

\section{Preliminary Results}

a. Cognitive disorders mainly concerned memory and attention.

b. MMSE was found to be non-specific for the detection of disorders since $91 \%$ of patients had a final score of over $25 / 30$.

c. Very useful was the combination of the interview with the SKT. $57 \%$ of the patients had difficulty recalling earlier memories of objects of everyday life such as cups, umbrellas, chairs, dogs, etc. $35 \%$ of them had memory disturbances (in the same objects) and only $18 \%$ of patient disorders in the memory of recognition. Difficulty in classifying numbers found in $20 \%$ of patients attributed more to attention disturbance than to critical impairment.

d. Cognitive fatigue was found at $57 \%$ of the patients, especially when they were tasked with evaluating numerous parameters at the same time. This disorder was particularly evident in patients with university education and those with 
increased professional responsibilities, causing difficulties in their daily functioning, with consequent anxiety disorder which increased their cognitive fatigue and decreased their self-esteem. An indication of cognitive fatigue was manifested as a disturbance of attention and concentration. University students who suffered from MS noticed that they could not concentrate and that they had to take many breaks in order to achieve the desired result.

e. $\quad 43 \%$ of the patients showed difficulties in classifying and organizing priorities in their daily life, resulting in easy loss of control and this lead them to anxiety and panic attacks. Most of them admitted that they felt safe following their daily routine and became terrified to the idea of any sudden change even on simple issues.

f. Most of the cognitive disorders were characterized as mild to moderate, causing difficulties in the everyday life. g. Two patients, suffered from SPMS for more than ten years, were diagnosed with dementia, showed high disability status and the greatest demyelination in the cerebral lobes.

\section{References}

1. Kalatha T, Koutsouraki E, Arnaoutoglou M (2018) Cognitive impairment in a Greek MS patient cohort using bicams. J Neurol Neurosurg Psych 89(10): 20.

2. Kalatha T, Koukoulidis T, Hatzifilippou E, Kalathas T, Bouras M, et al. (2018) The correlation between cognitve disorders and clinical parameters in multiple sclerosis patients. $1^{\text {st }}$ Poster Prize in $59^{\text {th }}$ International Neuropsychiatric Pula Congress.

3. Polman CH, Reingold SC, Banwell B, Clanet M, Cohen JA, et al. (2011) Diagnostic Criteria for Multiple Sclerosis:2010 Revisions to the McDonald Criteria. Ann Neurol 69(2): 292-302.

\section{Your next submission with Juniper Publishers will reach you the below assets}

- Quality Editorial service

- Swift Peer Review

- Reprints availability

- E-prints Service

- Manuscript Podcast for convenient understanding

- Global attainment for your research

- Manuscript accessibility in different formats ( Pdf, E-pub, Full Text, Audio)

- Unceasing customer service

Track the below URL for one-step submission https://juniperpublishers.com/online-submission.php 